\title{
Choice of skin incision for a massive ovarian cyst
}

\section{H. Annamraju, R. Rehman, E. Opara}

Department of Obstetrics and Gynaecology, Wexham Park Hospital, Slough, UK

Email: drhbindu@yahoo.co.uk

Received 12 April 2013; revised 14 May 2013; accepted 22 May 2013

Copyright (c) 2013 H. Annamraju et al. This is an open access article distributed under the Creative Commons Attribution License, which permits unrestricted use, distribution, and reproduction in any medium, provided the original work is properly cited.

\begin{abstract}
We present a case of a very large ovarian cyst extending up to the patient's xiphisternum, which was managed through a Pfannensteil incision. The cyst was excised without any spill of fluid, using a $5 \mathrm{~mm}$ laparoscopic port under suction, through a Pfannensteil incision. By this method, the operating time and the post-operative in-patient stay were reduced. Also, as our patient had a very high BMI, the associated morbidity was significantly reduced.
\end{abstract}

Keywords: Ovarian Mucinous Cystadenoma; Laproscopy; Pfannensteil Incision; Obesity

\section{CASE REPORT}

A 43 years old nulliparous Caucasian lady was referred to the Gynaecology department by her GP with irregular bleeding and bilateral pelvic pain. There was no history of weight loss or loss of appetite. She was clinically obese with a BMI of 40 .

On examination, a cystic mass was palpable abdominal, but it was difficult to delineate the upper limit. Abdominal, pelvic and transvaginal ultrasound scan showed a large midline structure, measuring $25 \times 16 \mathrm{~cm}$. Left ovary was seen separately, and the right ovary could not be seen. Clear regular endometrial echo of $12 \mathrm{~mm}$ was seen. Her CA 125 was $20 \mathrm{U} / \mathrm{ml}$.

She had an urgent MRI pelvis (Figures 1 and 2), which showed a large $28 \times 30 \times 15 \mathrm{~cm}$ fluid filled right ovarian cyst, arising from the pelvis and extending into the abdomen to the level of the renal hilum. It was largely unilocular but had a thickened septum and mild mural thickening at its inferior posterior aspect. It also had further thin septations, but no significant solid component, or haemorrhagic content. The left ovary and uterus appeared normal. There was no free fluid or lymphadenopathy. The limited upper abdominal imaging suggested mild right pelvi-caliceal dilation/hydronephrosis.

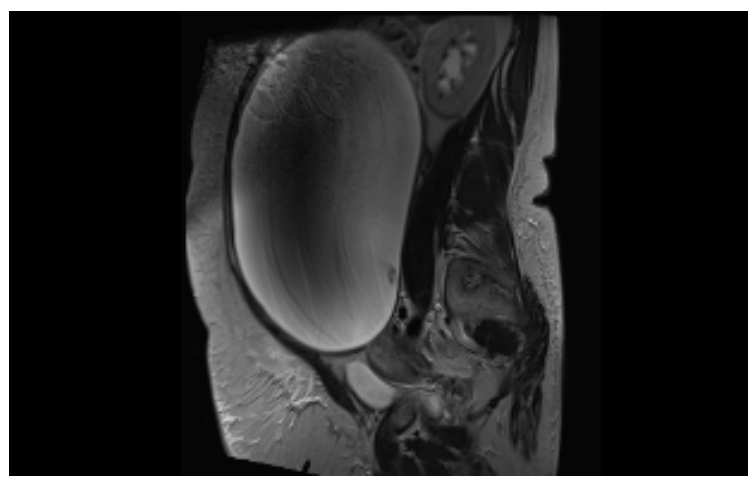

Figure 1. MRI image of the ovarian cyst.

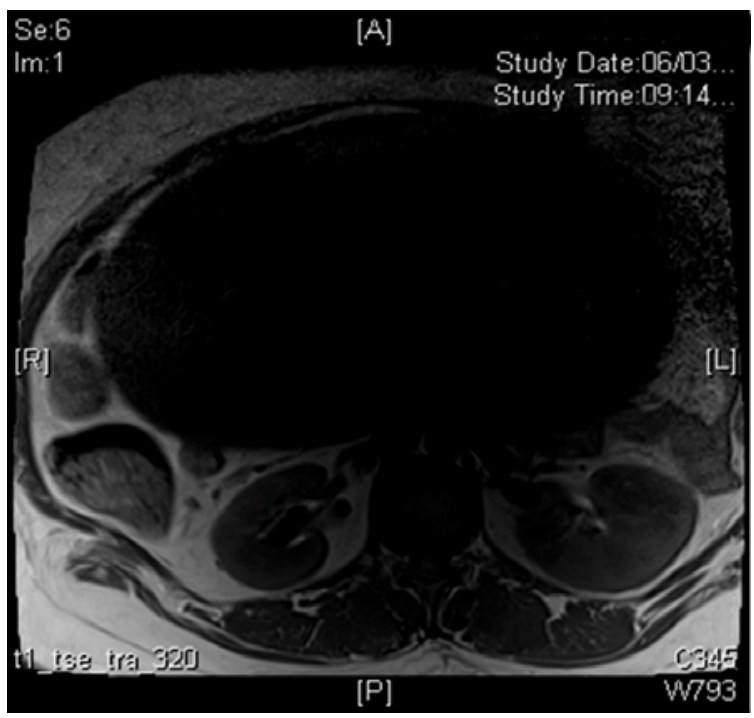

Figure 2. MRI image of the ovarian cyst.

These findings were discussed at the multi-disciplinary team meeting and the decision was made for a laparotomy and removal of the ovarian cyst \pm oophorectomy. It was considered to be benign.

At surgery, it was decided to perform a low transverse abdominal incision. On opening the abdomen, the cyst appeared simple, and extended up to the xiphisternum.

A $5 \mathrm{~mm}$ trocar was inserted into the cyst and secured 
with a purse-string suture. Care was taken during insertion, to ensure that there was no leakage of the cyst fluid. The trocar was then connected to suction apparatus and the cyst fluid was aspirated. 9.3 litres of straw coloured fluid were aspirated.

Subsequently, the right ovarian cyst wall was excised with the right fallopian tube (Figure 3). There was no discernible ovarian tissue. These were sent for histology. The cyst fluid and peritoneal washings were sent for cytology. The abdomen was closed in layers.

The patient had an uneventful recovery, and she was discharged home on Day 2. The cytology confirmed no malignant cells in the cyst fluid. The histology of the cyst was reported as benign mucinous cystadenoma of the ovary, with no evidence of malignancy.

\section{DISCUSSION}

Mucinous cystadenomas are known to be benign ovarian tumours [1], commonly seen in middle aged women. Spillage of cyst contents into the peritoneal cavity can result in chemical peritonitis and formation of adhesions [2]. Also, it is important to prevent spread of possible malignant cells throughout the peritoneal cavity, until histology confirms absence of malignant cells [3].

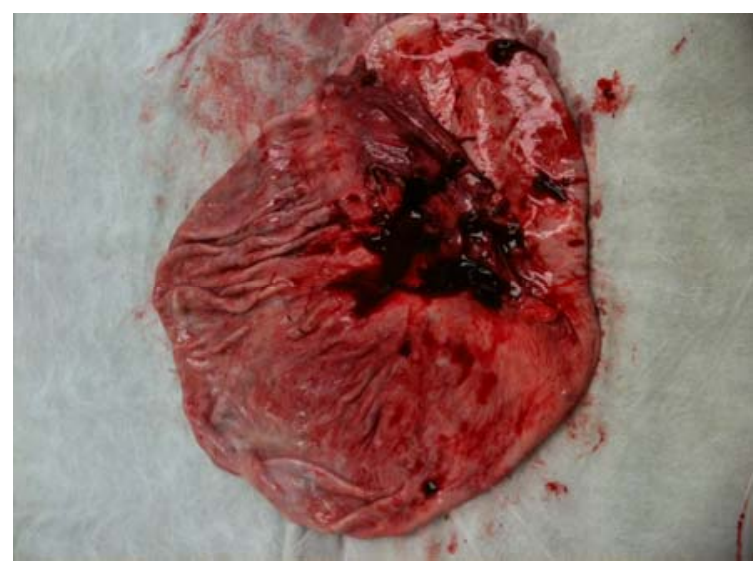

Figure 3. Collapsed ovarian cyst, excised completely with no discernible ovarian tissue.
Hence, a good operative technique is essential.

Most previous published cases report removal of the cyst intact, through a midline laparotomy. This would be completely justified, given the argument above. However, in patients with other co-morbidities, like our patient with Grade 3 obesity, it is imperative to balance her surgical needs with her post-operative recovery and possible complications, including delayed wound healing and wound dehiscence.

Laparoscopy is not an option in this case for obvious reasons. Hence on balance, a transverse abdominal incision was considered appropriate. The operation was carefully planned to avoid any spillage of cyst contents.

\section{CONCLUSION}

In cases of very large benign ovarian cysts confirmed by normal CA 125 and MRI pelvis, choice of abdominal incision should be considered carefully along with patient's co-morbidities. Pfannensteil incision should be considered, provided that adequate steps are taken to avoid spillage of cyst contents. This does help reduce the intra-operative time and post-operative recovery time for the patient.

\section{REFERENCES}

[1] Kamel R.M. (2010) A massive ovarian mucinous cystadenoma: A case report. Reproductive Biology and Endocrinology, 8, 24. doi:10.1186/1477-7827-8-24

[2] Bolla, D., Deseö, N., Sturm, A., Schöning A. and Leimgruber C. (2012) Minilaparotomy a good option in specific cases: A case report of bilateral ovarian germ cell tumor. Case Reports in Obstetrics and Gynecology, 2012, 589568.

[3] Stitely, M.L. (2012) Laparoscopic removal of a large ovarian mass utilizing planned trocar puncture. Journal of the Society of Laparoendoscopic Surgeons, 16, 148-150. doi:10.4293/108680812X13291597716465 